\title{
Notices and Announcements
}

\section{Nominations for the Editorship of Perception \& Psychophysics}

Nominations are solicited for the editorship of Perception \& Psychophysics. The term of the present editor, Myron Braunstein, expires at the end of 1998. The new editor will begin an official 4- or 5-year term on January 1, 1999, and will begin to receive manuscripts early in January 1998. The Publications Committee of the Psychonomic Society expects to appoint the new editor by November 1997.

Nominations (including self-nominations) should be submitted by August 1, 1997, to:

\author{
Stephen Palmer \\ Chair, Perception \& Psychophysics Search Committee \\ Department of Psychology \\ University of California \\ Berkeley, CA 94720-1650
}

\section{Nominations for the Editorship of Psychonomic Bulletin \& Review}

Nominations are solicited for the editorship of Psychonomic Bulletin \& Review. The term of the present editor, Henry L. Roediger III, expires at the end of 1998. The new editor will begin an official 4- or 5-year term on January 1, 1999, and will begin to receive manuscripts early in January 1998. The Publications Committee of the Psychonomic Society expects to appoint the new editor by December 1997.

Nominations (including self-nominations) should be submitted by August 31, 1997, to:

Geoffrey Loftus

Chair, Psychonomic Bulletin \& Review Search Committee

Department of Psychology

University of Washington

Seattle, WA 98195 


\section{Call for Papers on Teaching Demonstrations and Tutorials}

Many phenomena and concepts in behavioral research can be illustrated to students most effectively through software and video demonstrations and tutorials. A limiting factor in the use of such materials by instructors is knowledge of their existence and lack of easy accessibility. In part to remedy this situation, I am inviting submission of manuscripts describing demonstrations, tutorials, and experiments that can be used in instructional settings to further education regarding behavioral research. Manuscripts received by November 1, 1997, will be considered for a special issue or section of Behavior Research Methods, Instruments, \& Computers devoted to teaching demonstrations and tutorials. It is my hope that all individuals who have developed materials of this nature that would be of interest to a range of instructors will submit manuscripts and make the materials described in them readily available. The teaching demonstrations and tutorials of authors who consent will be placed at a Web site from which they can be accessed. Manuscripts should be sent in quadruplicate to Robert W. Proctor, Department of Psychology, Purdue University, 1364 Psychology Building, West Lafayette, IN 47907-1364.

Robert W. Proctor, Editor

Behavior Research Methods, Instruments, \& Computers

\section{$\int_{Q A B}$}

\section{Society for the Quantitative Analyses of Behavior}

SQAB holds its annual meeting in conjunction with ABA, this year at the Sheraton Chicago Hotel on Thursday, May 22 and Friday, May 23, 1997. Talks focus on the development and use of mathematical formulations to: characterize one or more dimensions of an obtained data set, derive predictions to be compared with data, and generate novel data analyses.

This year presentations will be given by Rachlin; Hursh \& Winger; Belke; Stojanov; Kubota; Collier; Shimp, Fremouw, \& Herbranson; Bitterman \& Couvillon; Myerson \& Green; Case; Jones \& Davison; Luce; Lau \& Falk; and Newland \& Reile. SQAB is also sponsoring four Preeminent Tutorials (From Basics to Contemporary Paradigms: ...) during the ABA meeting on Friday afternoon (Hineline, Townsend, Fantino and Heyman), as well as Breakfast Tutorials (Machado) preceding the SQAB morning sessions.

Visit our Web page for abstracts and additional information. Registration fees will be waived for students presenting quantitative papers or posters at ABA or SQAB. Send requests for registration/membership information or poster submissions to:

William L. Palya, SQAB Program Chair

Jacksonville State University, Jacksonville, AL 36265

http://jsucc.jsu.edu/psychology/sqab.html

palya@sebac.jsu.edu (205-782-5641 voice) (205-782-5680 fax) 